\title{
Globalização e saúde globlal
}

GIOVANNI BERLINGUER

\section{Globalização? Qual?}

$\mathrm{F}$

ALA-SE MUiTO HOJE em globalização. As finanças, a informação simultânea, as migrações de povos, o crime organizado, os conhecimentos científicos, a tecnologia, os sistemas de poder, a produção e o trabalho humano, tudo isso se globaliza.

Pode-se exaltar a globalização como oportunidade de crescimento econômico e cultural dos povos. Pode-se ainda criticá-la em razão dos que a conduzem, ou de como a conduzem, ou dos rumos que toma. Mas ela é irrefreável, sobretudo por corresponder a muitas exigências dos seres humanos.

Essa afirmação pode sofrer duas objeções: uma vem sustentar que a globalização da economia corresponde hoje à acumulação de capital e de poder em poucas mãos e ao predomínio das finanças internacionais sobre qualquer outro interesse; outra, é que o conceito e a natureza da globalização foram criados e difundidos por forças neoliberais, com a intenção de levar os povos a crer que não há alternativa e, assim, de negar a função da política e da democracia.

Ambas as objeções baseiam-se em fatos reais. Pode-se acrescentar que o ganho de capital em nossos dias passou a não respeitar nada (a vida, a saúde e até mesmo as partes do corpo humano vão se transformando em mercadoria) e que o credo neoliberal é imposto aos povos com as regras do fundamentalismo monetário, que não admite dissidências. É o que se evidencia quando o Banco Mundial e o Fundo Monetário Internacional subordinam sua ajuda ao compromisso dos governos de desmantelar os sistemas de saúde pública e previdência social. As conseqüências dessa opção (e ainda mais, dos crescentes desníveis de renda, de educação e de poder entre as classes e entre os povos) traduziram-se por quase toda a parte, nos últimos 20 anos, em aumento das desigualdades de níveis de saúde, documentadas por estatísticas eloqüentes, que se podem traduzir em milhões de existências humanas truncadas ou prejudicadas.

Deve-se acrescentar, contudo, que nos últimos anos as reações a essa situação e as iniciativas pela igualdade na saúde (a partir do lançamento do 
projeto Global equity in health de fevereiro de 1996) multiplicaram-se com ritmo e expansão imprevistos, tanto que puseram o tema na ordem do dia das políticas de saúde em muitos países e no plano internacional. Isso também é globalização, que pode ser levada a cabo não só por motivos específicos, relativos à saúde, mas porque o clima cultural e moral do mundo está mudando.

Há 20 anos esperanças e ilusões se voltavam para o poder saneador do mercado, que a ideologia neoliberal havia transformado, do que sempre foi (ou seja, estímulo oportuno e regulador da economia), em deus onipotente e benévolo, que acabou por se revelar caprichoso e cruel. De fato, nuvens escuras pairam sobre a economia mundial e a preocupação passa a dominar o pensamento de toda a gente. O que se pergunta agora é quais as implicações, no plano moral, do aumento das desigualdades. Pergunta-se também se, além de certos limites, essas desigualdades não podem tornar problemática a convivência nas nações e entre as nações. No plano político, é no consenso popular que se buscam e se constróem, sobretudo na Europa, as alternativas de governo que pareciam excluídas para sempre.

A verdadeira pergunta, por isso, não é se a multiplicação das relações internacionais e a maior independência são um bem ou um mal e se devem ser favorecidas ou cerceadas. A pergunta é outra: qual a globalização, para que fins, em que rumo?

\section{Globalização e saúde}

Tentarei dar uma resposta parcial a essa pergunta, observando a realidade através do prisma da saúde, entendida com bem-estar individual, como interesse coletivo e como condição essencial de vida em liberdade. De fato, a liberdade substancial diminui quando predomina a doença: porque o indivíduo fica em geral impedido de exercer uma ou mais de suas faculdades de decidir e de agir; porque sua sorte passa a ser confiada a outros poderes, sobretudo quando o doente enquanto tal não é mais considerado cidadão portador de direitos; porque a doença, quando persistente, muitas vezes leva o indivíduo (e as nações) a um movimento para baixo, a um círculo vicioso de regressão, que traz o risco de se tornar irreversível.

Até agora, muitas análises da relação entre globalização e saúde encararam a saúde como subproduto, como conseqüência espontânea - positiva, segundo alguns, negativa, segundo outros - de forças globalizadoras estranhas a essa exigência e motivadas somente por outros interesses. Em lugar disso, proponho uma óptica inicialmente descritiva e depois normativa. 
Sublinho que a saúde deve ser encarada hoje como problema global, e que sua globalização é um bem pelo qual há de se trabalhar de modo explícito e programado. Acrescento que se devem corrigir e guiar as tendências atuantes, até mesmo por ser paradoxal que a globalização, tão preponderante e invasiva, deixe ficar descuidado ou deteriorado um bem tão essencial quanto a saúde. A saúde global é uma finalidade social desejável, hoje descuidada ou deformada pela influência do fundamentalismo monetário, mas merecedora de evidência prioritária, seja por seu valor intrínseco, seja como símbolo do predomínio de valores humanos sobre outros interesses.

A luta contra as desigualdades é um poderoso estímulo para esse objetivo. Mas, no plano prático, tem o mesmo valor, senão maior, a consciência de que a saúde é um bem indivisível, e de que o gênero humano está vinculado por um destino comum. Os últimos anos fizeram crescer no mundo a consciência ambientalista, baseada na verificação elementar de que vivemos em um único planeta. Ainda não aconteceu o mesmo no tocante à consciência da saúde. Nessa passividade generalizada, que peso terão tido os silêncios interessados de quem detém o saber, o oportunismo de quem detém o poder (a começar pela Organização Mundial de Saúde), a cumplicidade da política e, afinal, as distorções das ciências médicas, fortemente avessas a reconhecer que a origem das doenças está, fundamentalmente, onde se entrelaçam o biológico e o social?

Começarei esta exposição pela ameaça mais grave e difundida: as doenças, recordando alguns aspectos da história moderna. Farei alusão aos resultados obtidos, e à regressão (relativa) das últimas décadas. Descreverei alguns danos e riscos que se estão acumulando em escala global: infecções, poluição ambiental, tóxicos, violência. Concluirei com algumas observações de caráter predominantemente moral.

\section{A unificação microbiana do mundo}

A globalização das doenças, ou seja, a difusão dos mesmos quadros mórbidos por todas as partes do mundo começou no ano de 1492, com a descoberta (ou conquista) da América, que assinalou, para povos e doenças, a passagem da separação à comunicação. Antes disso, diferentes condições de ambiente, de nutrição, de organização social e cultural, de presença ou ausência de agentes e de vetores biológicos das doenças transmissíveis haviam criado quadros epidemiológicos muito desiguais, no velho e no novo mundo.

Nas Américas, por exemplo, não existiam varíola, sarampo, febreamarela, ao passo que na Eurásia e na África não havia sífilis. A sífilis mani- 
festou-se de forma epidêmica, pela primeira vez no velho mundo, em 1495, com a conquista de Nápoles pelas tropas francesas de Carlos VIII. Os italianos por isso a chamaram de mal francês, enquanto os franceses, de mal napolitano. Quando chegou ao Oriente, os japoneses a denominaram de mal português e a estigmatização foi assim por diante. A tendência a culpar outros pelas epidemias é constante na história. Os judeus foram acusados de introduzir a peste negra na Europa; os irlandeses, de introduzir o cólera em Nova York; os italianos, a poliomielite no Brooklyn. E deve-se lembrar que a primeira definição da aids, formulada pelo Center for Disease Control (CDC) de Atlanta ao identificar a doença, foi a seguinte: imunodeficiência adquirida dos homossexuais.

Desde 1492 foi devastador o impacto das novas doenças em populações desprovidas de qualquer imunidade natural, sobretudo no continente americano, e representou uma das causas do maior genocídio ocorrido em toda a história da espécie humana. Uma das principais causas, certamente. Muitos historiadores, porém, consideram que a ênfase exclusiva nesse fator, derivado de um fenômeno então incoercível (ou seja, a relação entre microorganismos e defesas biológicas humanas), obscurece as demais causas responsáveis pelo extermínio. Causas que devem se buscar na perda da identidade, de segurança e de poder dos povos do novo mundo, e portanto no extermínio deliberado, no trabalho escravo e mortífero das minas, na ruptura de equilíbrios alimentares e no colapso psicológico e cultural que reduziu a resistência às doenças e causou até mesmo epidemias de suicídio.

A partir do século XVI realizou-se, portanto, a unificação microbiana do mundo. Mas haviam de passar três séculos antes de a humanidade (povos, governos, cultura e ciência) tomar consciência dos riscos comuns, afirmar a existência de direitos fundamentais de todos os seres humanos e começar a combater esses riscos com empenho que ultrapassou fronteiras.

\section{A globalização no século XIX}

Somente no século XIX consolidou-se a idéia de que, embora o mercado fosse fator de progresso na economia, algo tinha de lhe permanecer estranho: em primeiro lugar os seres humanos, pois de outra forma ficariam comprometidas a segurança e a dignidade de todos. Sobre esse fundamento começaram a se formular regras e proibições contra a escravidão, que depois se tornaram universais. Mas o principal é que apenas no século XIX foi que se verificaram os três pressupostos de uma ação eficaz contra as doenças transmissíveis encontradas em todos os países e, acima de tudo, grandes causadoras de mortes. Esses pressupostos foram: o conhecimento 
das causas dessas doenças; a determinação de remédios preventivos e terapêuticos; a vontade de combatê-las no plano internacional.

O primeiro exemplo dessa ação ocorreu ainda em fins do século XVIII e foi a vacinação contra a varíola, já praticada havia muito tempo na Ásia, onde se usava soro extraído das pústulas variólicas curadas. A Europa conheceu a vacina por meio da Turquia, onde curandeiras conseguiam provocar em crianças uma forma atenuada da doença, que lhes dava imunidade permanente.

Tal sistema não se difundiu na Europa provavelmente pela cegueira epistemológica e pela arrogância profissional dos médicos europeus, que julgavam nada ter de aprender com gente que seu preconceito considerava três vezes subdesenvolvida intelectualmente: mulheres, curandeiras e turcas. A vacinação difundiu-se pela Europa, e de lá para o mundo, quando Jenner (que também se valeu da experiência feminina popular) reinventou e aperfeiçoou a vacina, demonstrando-lhe a eficácia em larga escala.

As décadas que medeiam os séculos XIX e XX foram a época de maior progresso na luta contra as doenças epidêmicas. Descobriram-se muitos micróbios, agentes de infecções difundidas e mortíferas, como a tuberculose, a peste, o cólera-morbus. Descobriram-se também seus modos de transmissão, mediante vetores artrópodes ou contaminação de alimentos e água. Introduziram-se soros e vacinas. Sanearam-se muitas cidades. Votaram-se leis para reduzir a jornada de trabalho de 12 ou 14 para oito horas. Votaram-se benefícios para gestantes e limitações ao trabalho de menores. Difundiram-se o seguro social e outra formas de tutela coletiva da saúde. Estabeleceram-se acordos entre os países contra a passagem de doenças de uma parte do mundo a outra e criou-se, com a Agência Internacional contra Epidemias, o primeiro embrião de um organismo mundial de saúde.

É interessante lembrar que muitas descobertas de agentes biológicos e de vetores de doenças epidêmicas foram feitas por médicos ou comissões científicas militares que trabalhavam em exércitos coloniais. Foi assim que se descobriram, no Norte da África, o plasmódio da malária; na Índia, a função das pulgas e ratazanas na transmissão da peste; na América Central, o papel do Aedes aegypti como vetor da febre amarela, na época da abertura do canal do Panamá.

Essas pesquisas foram incentivadas porque as doenças atingiam os exércitos e os colonos, além da população local, e eram indispensáveis novos conhecimentos para estabilizar a conquista e a exploração. Mas todos se beneficiaram com isso, incluídas (em menor grau) as populações locais. 
Como resultado de múltiplos fatores, e também da convergência de interesses diferentes, naquelas décadas ocorreu pela primeira vez uma regressão estável dos flagelos eternos da humanidade, sendo aberto o caminho para o aumento da expectativa de vida da espécie humana. Esse fato, embora ocorrido de modos bem diferentes no tempo histórico e no espaço geográfico do globo, e embora mantidas desigualdades substanciais entre povos e classes, sem dúvida representa no século XX extraordinário progresso social e biológico. Sabemos que este século trouxe duas guerras mundiais, inúmeras guerras locais, genocídios, violência. Mas vale, ainda assim, o juízo do historiador Toynbee: “O século XX será lembrado principalmente não como época de conflitos políticos ou invenções técnicas, mas como época em que a sociedade humana ousou pensar na saúde como objetivo prático realizável”.

\section{A regressão das últimas décadas}

Apesar disso, não tenho certeza de que é assim também que as últimas décadas serão lembradas. Minha impressão deriva, em primeiro lugar, dos fatos: a queda de muitas esperanças, o retardamento do progresso sanitário, o aumento de diferenças e desigualdades tanto no plano da saúde quanto no grau de segurança externa das nações e da segurança interna de muitas delas. Deriva também dos rumos culturais que estão predominando em grande parte dos países, e que se podem resumir nos seguintes pontos:

- A Organização Mundial de Saúde, por seus defeitos e pelo desinteresse dos governos, perdeu a função de guia nas políticas mundiais de saúde. O poder e as influências, neste campo, passaram ao Banco Mundial e ao FMI, que hoje são líderes essenciais em questões de saúde, sobretudo para os países menos desenvolvidos.

- A idéia de saúde como fundamento (por ser multiplicador dos recursos humanos) e sobretudo como finalidade primordial do crescimento econômico foi quase universalmente substituída pela idéia oposta: que os serviços públicos de saúde e a generalização dos tratamentos são obstáculo, e muitas vezes principal obstáculo, para as finanças públicas e para o desenvolvimento da riqueza. É assim que o maior imperativo de qualquer governo passa a ser a redução das despesas com saúde (não a racionalização dessas despesas, o que é indispensável em todos os países!).

- O modelo que atribuía à primary health care função preventiva e terapêutica essencial foi substituído em muitos países pela tendência a desmontar os mecanismos de intervenção pública, a atribuir, mesmo 
onde os recursos são mínimos, prioridade a tecnologias dispendiosas e reservadas a pouquíssimos privilegiados; a substituir os serviços comunitários por seguros particulares, que nos Estados Unidos se revelaram o sistema mais caro e menos equitativo de assistência de saúde; enfim, a deixar aos cuidados do Estado somente os pobres, exatamente como se dava na Europa do século XIX!

- A idéia de a saúde mundial ser indivisível, idéia que foi crucial no início do século e serviu de fundamento à criação da OMS, foi substituída pela conviç̧ão, muito difundida na Europa e nos Estados Unidos, de que os povos podem gozar o máximo de saúde isolados dos sofrimentos de outros povos. A mesma ilusão se difundiu dentro de cada país, junto aos grupos sociais sadios e ricos diante dos problemas e tragédias dos outros.

Eu não vejo o futuro com pessimismo, mas entendo que médicos, enfermeiros, cientistas, associações, entidades de governo ou não, todos os que trabalham no campo da saúde têm uma nova obrigação perante a sociedade. Ao sigilo profissional, que obriga os médicos com relação às doenças de quem lhes confia a vida, acrescenta-se, para todos os que têm conhecimento, o dever social de alertar, de informar as populações e as instituições sobre as ameaças que põem em risco a saúde e a segurança da comunidade.

Hoje manifestam-se, nesse campo, quatro fenômenos muito preocupantes (a escolha pode ser arbitrária, e espero que outras análises venham suprir as limitações desta que faço). Não são somente riscos, mas danos crescentes à saúde e à integridade individual e coletiva: doenças e, além disso, problemas de patologia social que produzem nos seres humanos conseqüências destruidoras semelhantes às das doenças. São os seguintes: recrudescência de antigas infecções e surgimento de novas; poluição ambiental, em suas implicações para com a saúde; mundialização dos tóxicos; formas de violência destruidora e autodestruidora.

\section{Antigas e novas infecções}

O extraordinário resultado da redução da mortalidade por doenças infecciosas em todos os países alimentou, nas últimas décadas, a esperança de um mundo sem epidemias.

A permanência da vulnerabilidade das populações diante dos micróbios e dos vírus foi, infelizmente, demonstrada nos anos 70 e 80 pelo aparecimento e identificação do vírus da aids, que se difundiu rapidamente quase por toda a parte. E também por outros fenômenos: o aparecimento 
de novos agentes viróticos, até agora felizmente confinados a algumas regiões; a transmissão intercontinental de doenças que se julgavam subsistentes somente em alguns países, como o cólera-morbus; a endemia de malária, que a cada ano faz milhões de vítimas na África e em outras áreas do hemisfério Sul (e que se estendeu até a Virgínia, nos Estados Unidos); a recrudescência e a virulência de micróbios como Mycrobacterium tuberculosis, com o aumento de casos mesmo na Europa e nos Estados Unidos.

A explicação mais comum desses fenômenos é o aumento exponencial e a rapidez das viagens de homens e mulheres por todas as partes do mundo. É verdade, mas só em parte. A encefalopatia espongiforme bovina (BSE) espalhou-se pela população humana da Grã-Bretanha simplesmente porque os criadores haviam alimentado as vacas com carne, tripas e miolos de ovinos, transformando, por sede de lucro, respeitáveis herbívoros em carnívoros e abrindo o caminho ao contágio entre espécies. A tuberculose aumenta não só por ser infecção oportunista nos doentes de aids, mas também por crescerem a pobreza e a marginalidade urbanas, o trabalho de crianças e o uso inadequado e indiscriminado de medicamentos antimicrobianos, o que provocou a seleção de organismos resistentes a eles.

A persistência de doenças microbianas e parasitárias, como a malária, deriva também da falta de investimentos na pesquisa de vacinas. Esses investimentos estão na proporção de um para cem, comparados os casos da aids e da malária, mas a única diferença objetiva é que a Aids pode matar ricos e pobres.

E as viagens internacionais? Não se fazem somente por turismo, por cultura, por necessidade de trabalho. Nos últimos dez anos, 50 milhões de homens, mulheres e crianças tiveram de se deslocar de um país a outro por motivo de fome, convulsões civis, golpes de Estado, guerras: tragédias que ao longo da história, sempre têm sido pródromo de doenças.

Tais fenômenos nos levam a refletir sobre a transição epidemiológica. Em geral considera-se que essa transição, como fenômeno nosológico dominante, consiste na passagem de doenças infecciosas a doenças crônicodegenerativas, ou melhor, não-infecciosas. Essa análise vale para as estatísticas de mortalidade mas requer alguns reparos.

Em primeiro lugar, tal análise não se pode aplicar às estatísticas de algumas doenças que ainda não são relevantes em muitas partes do mundo.

Em segundo lugar, o reaparecimento de velhas infecções e o surgimento de novas deve nos induzir a não esquecer que insetos, vírus, micróbios e parasitas viajam sem passaporte e passam sem visto pelas fronteiras. 
"Desde que o mundo se tornou menor, graças aos atuais meios de comunicação ... a solidariedade humana no campo da saúde não pode ficar impunemente descuidada", como escreveu Henry Sigerist em Civilization and disease, no ano de 1943, ou seja, há 56 anos.

Em terceiro lugar, se para além da mera descrição quisermos encontrar uma explicação casual, a transição epidemiológica representa também (ou principalmente) a transição de doenças fisiogênicas, que tinham origem preponderantemente natural, a doenças preponderantemente antropogênicas, cuja origem se deve buscar em nós mesmos, seres humanos, em nossas ações e/ou omissões, na falta de concepções previdentes e solidárias. Portanto, sendo fenômenos antropogênicos, não são fatais nem irreversíveis: podem ser dominados e modificados.

\section{Alarma médico em prol do ambiente}

A deterioração ambiental, esta sim, apresenta riscos de situações irreversíveis. Muitas transformações do ambiente melhoram a saúde: o saneamento urbano, por exemplo, foi decisivo para a luta contra as doenças transmitidas pela água e pelos alimentos (por via oro-fecal); como também o aumento da produtividade agrícola, que compreende o uso da química e da biotecnologia na luta contra a fome.

Nas últimas décadas, porém, acentuaram-se os danos imediatos, que, embora em diferentes graus, atingem todos os povos e classes. São danos que derivam: da poluição do ar, das águas, do solo e do subsolo, como também do empobrecimento dos recursos naturais e da qualidade de vida nos conglomerados urbanos, onde se está concentrando a maioria da população mundial. $\mathrm{O}$ contraste entre ostentação de riqueza e disseminação da pobreza é um dos fatores que aumentam a criminalidade, sobretudo nas megalópolis de países pobres.

Ainda mais preocupantes são os riscos para o futuro. The New York Times publicou, em $1^{\circ}$ de dezembro de 1997, um apelo de médicos, no qual são ressaltados os possíveis efeitos do aquecimento global (global warming):

“1. Doenças e mortes crescentes, derivadas de ondas de calor e poluição atmosférica, em especial nas áreas urbanas, com riscos principalmente para idosos, crianças, pobres e portadores de moléstias cardíacas e pulmonares.

2. Aumento de lesões e mortes derivadas de ocorrências climáticas extremas. 
3. Explosão e difusão de algumas doenças infecciosas transmitidas por mosquitos, entre as quais a encefalite virótica, a dengue, a febre-amarela e a malária.

4. Propagação de algumas doenças transmitidas pela água, como diarréias infantis e cólera-morbus.

5. Menor disponibilidade de água potável, por efeito de secas, de inundações e do aumento no nível dos mares.

6. Enfim, o que é talvez a maior preocupação: efeitos prejudiciais aos organismos que vivem na terra e nos oceanos, o que poderia afetar a produção de alimento e alterar o funcionamento do ecossistema que torna possível a vida em nosso planeta."

Os cientistas signatários do apelo reconhecem explicitamente que "há muitas incertezas nessas previsões, alguns efeitos sobre a saúde talvez não sejam tão graves quanto se prevê". Mas duas considerações se impõem. Uma é ditada por motivos de ordem prática. Embora a gravidade dos danos seja imprevisível, muitos deles já se podem perceber. E a pergunta crucial, acima de tudo, é esta: pode-se deixar de agir quando, apesar da incerteza de alguns desdobramentos, há certeza de que em caso de inação esses desdobramentos serão irreversíveis?

Outra consideração é de caráter moral. As conseqüências dos danos já conhecidos e os riscos das transformações ambientais muitas vezes se dão em lugares distantes de quem as provoca, atingindo seres humanos antes mesmo de nascerem. Os cálculos de danos/benefícios e riscos/benefícios nesses casos são absolutamente insustentáveis, pela total disparidade de sujeitos: alguns (poucos) beneficiários; outros (muitíssimos) ameaçados e lesados. Parecem também insuficientes as regras áureas da ética, baseadas na relação com o próximo. O que pode valer é o princípio de responsabilidade, enunciado por Hans Jonas, que compreende, além da ética de proximidade, uma ética da distância, e que por isso tem como objeto, por uma parte, o espaço mundial e, por outra, o tempo das gerações futuras. Isso implica capacidade de previsão e prevenção, que se pode manifestar somente no plano mundial, e que requer alterações na ética pública e no Direito.

\section{Dois circuitos dos tóxicos: de Sul a Norte e de Norte a Sul}

Para as gerações presentes, e sobretudo para os jovens, os tóxicos são um risco fundamental. Ao dano psicofísico decorrente de seu abuso, somase a presença da criminalidade, organizada muitas vezes em plano multinacional, que induz ao consumo e movimenta lucros enormes, lava- 
dos por meio de sistemas bancários coniventes ou complacentes. Lucros destinados a apoiar empreendimentos econômicos ilegais e, em alguns casos, a alimentar a corrupção política.

As discussões mais acirradas, que mobilizam os que têm consciência dos riscos dos tóxicos para a saúde e a segurança, tratam, antes de mais nada, do modo de transformar os cultivos, no caso de países exportadores de ópio e cocaína. Tratam também da estratégia de limitar o prejuízo, a fim de evitar que aos efeitos intrínsecos da dependência de tóxicos se acrescentem, por um lado, o aumento das atividades criminosas e, por outro, conseqüências irreparáveis para a saúde, como a difusão da aids por meio de seringas infectadas, usadas no consumo de heroína. Tratam, afinal, da eventual legalização das drogas leves, e da ministração supervisionada de heroína.

Não me deterei nessas discussões, nas quais confluem a necessidade de segurança - individual e coletiva - e o desejo de solidariedade para com os dependentes de tóxicos. Além disso, nessas discussões mostra-se muitas vezes difícil conciliar exigências práticas, preconceitos ideológicos e sistemas de valores.

Só desejo ressaltar um fato pouco observado. As Nações Unidas criaram uma agência especializada para enfrentar o problema. Mas o que é paradoxal, e só se explica pelas relações de poder existentes na comunidade internacional e pelo domínio dos meios de informação, é que todo o alarme e todas as ações se concentrem exclusivamente no combate à cocaína, ao ópio e aos seus derivados. Drogas sem dúvida nocivas e mortíferas, que crescem nos países pobres do Sul e que ameaçam os países ricos do Norte. Deixam-se de lado e ficam esquecidos o álcool e principalmente o tabaco, cuja produção e, mais ainda, cuja difusão ocorrem mediante o Norte, e cujo consumo, pela ação de empresas internacionais, está invadindo os países do Sul.

A revista da OMS, World Health, registra: “o que atualmente mais preocupa o mundo no tocante ao tabaco é o aumento de consumo nos países menos desenvolvidos. Enquanto o mercado do tabaco diminui em $1 \%$ ao ano no Ocidente, o fumo no Sul aumenta a cada ano em $2 \%$... Os peritos prevêem que o câncer e outras doenças associadas ao fumo surgirão nesses países antes de estarem dominadas as doenças transmissíveis. Com isso, crescerá ainda mais o abismo entre países ricos e pobres”.

E o que vêm fazendo os governos e as organizações internacionais?

A União Européia, por exemplo, decidiu investir US\$ 2 milhões, com grande ênfase publicitária, na luta contra os tumores, em particular o cân- 
cer de pulmão; ao mesmo tempo, concedeu mais de US\$ 2 bilhões para incentivar o cultivo do tabaco na Europa e sua exportação para outras partes do mundo. Os Estados Unidos, por sua vez, nas últimas décadas doaram a países pobres US\$ 700 milhões em sementes de tabaco, com o compromisso de comprar depois as folhas, no quadro dos programas de ajuda chamados de Alimentos para a paz. Além disso, ameaçaram de sanções comerciais quatro países asiáticos, que não queriam permitir a entrada de cigarros norte-americanos. A World Trade Organization também considera que limitar a venda internacional de tabaco e cigarros seria grave violação das regras de livre comércio. Muito diferente é a sua atitude para com a cocaína, o ópio e seus derivados.

Não acrescento mais comentários a esses fatos, porque são evidentes por si, além de amargos. Somente faço a esse respeito três perguntas.

- Enquanto nós trabalhamos pela educação para a saúde e pela promoção da saúde, enquanto nos preocupamos com a vida dos cidadãos, será que podemos esquecer que (talvez pela primeira vez na história, e sem dúvida pela primeira vez em escala mundial) há poderosas organizações internacionais que, por interesses próprios, promovem ativamente comportamentos seguramente reconhecidos como nocivos e muitas vezes mortíferos?

- Será que temos de acreditar que a difusão de entorpecentes merece cuidado e requer intervenção somente quando está relacionada com organizações criminosas? Mas que passa a merecer proteção comercial e impunidade penal quando, embora globalmente mais destruidora da saúde e da vida, estiver associada a organizações industriais reconhecidas por lei?

- Enfim, o que estão fazendo as Nações Unidas, a OMS, a OMC, os governos dos países ricos e pobres para enfrentar essas distorções absurdas e para evitar, ou ao menos reduzir, esse morticínio anunciado?

\section{A violência e as formas de violência}

Não apresentarei aqui um quadro epidemiológico da violência. Lembrarei somente que em quase todos os países ela constitui a causa principal de morte de adolescentes e jovens, sobretudo de sexo masculino; que atormenta e destrói a integridade corporal e mental, além da vida, de milhões de mulheres e crianças; que perturba a consciência coletiva e convivência social. 
Há muitas estatísticas nesse campo, por vezes somente parciais, mesmo porque é difícil construir uma taxonomia das formas de violência. Há formas reais e virtuais, ou seja, existe uma realidade da violência que se espelha (agigantando-se) nas suas formas representadas ou imaginadas pela realidade virtual, a todo o momento contemplada por espectadores de cinema e televisão, principalmente crianças. Existem formas de violência que no campo penal são julgadas culposas, como os acidentes de trabalho, de trânsito e domésticos. Mas perante essas formas de violência os conceitos de negligência, imprudência, impericia, inobservância de leis e de regulamentos mostram-se insuficientes, pois estão em jogo ocorrências estatisticamente mensuráveis e previsíveis, provocadas por interesses econômicos. Entre eles, a produção de veículos motorizados, projetados e anunciados com as características precípuas de viajar além do limite de velocidade consentido em todos os países. Existem, e suscitam maior indignação, formas dolosas de violência: violência contra os fracos e violência dos fracos; violência e desrespeitos sexuais, quase sempre contra mulheres, e que finalmente foram reconhecidas como crimes em muitas legislações nacionais; violência contra crianças e contra idosos; violência nos estádios; violência contra animais, que começam a ser vistos como portadores de direitos, ou ao menos como dignos de respeito.

A análise das formas de violência não pode esquecer que o que caracterizou nosso século, além dos extraordinários progressos humanos, foram as guerras e genocídios, em certos aspectos sem paralelo na história. Isso deveria nos ajudar a compreender que muitas das raízes e das motivações das formas de violência, individual e coletiva, estão na intolerância e no desprezo pelo valor da vida humana.

Estes fenômenos não devem ser equiparados a fenômenos médicos, embora muitas vezes envolvam a medicina, por motivos diferentes e opostos. Às vezes, até, como autora e cúmplice de violência. Na União Soviética a psiquiatria foi usada durante décadas como instrumento de repressão política; na América Latina as ditaduras militares fizeram aflorar casos generalizados de cumplicidade de médicos na tortura de prisioneiros. $\mathrm{E}$ as notícias sobre esterilizações forçadas nas Suécia, praticadas até a década de 1960, e sobre lobotomias praticadas em muitos países europeus até época recente, fizeram-nos entender que ainda não é universal a aplicação não só do Código de Nüremberg, mas do princípio hipocrático "em primeiro lugar, não fazer o mal”.

Com mais freqüência a medicina é chamada a remediar a violência: tratar das vítimas e dos culpados. A decisão de alguns juízes (como também o pedido de alguns autores de crimes sexuais) de recorrer à castração 
física ou química para prevenir a repetição do delito vem suscitando amplas discussões. Apela-se às ciências biológicas e às ciências do comportamento para explicar os impulsos à criminalidade e à agressividade. Dessas pesquisas podem derivar conhecimentos importantes, mas não acredito que as formas de violência possam ser interpretadas exclusivamente com a categoria sócio-biológica da agressividade humana. Tal aspecto pode talvez oferecer base científica para compreender os casos particulares, ou fornecer um ponto de vista que é importante levar em conta, mas não pode explicar as oscilações espaciais e temporais (muitas vezes tendentes a aumentar) da violência global e dos tipos individuais de violência.

É difícil admitir que quando há violência em alguma parte do mundo - contra algum sexo ou etnia, contra uma idéia que existe na cabeça ou uma cor que distingue a pele, seja por motivos ideológicos ou religiosos, seja para vingar-se do mundo, quando há violência como forma de criminalidade organizada ou generalizada, ou como opressão política, ou ainda como ação e como reação - que alguém possa pensar "isso não é problema meu", e que possa isolar-se, ainda que tente proteger-se com uma dupla couraça de insensibilidade.

Assim como os tóxicos são transmissíveis por indução ao consumo, também as formas de violência são transmissíveis não só pela ação das organizações criminosas e às vezes mecanismos oficiais, mas ainda por vias materiais e culturais: por imitação, por sugestão, por transmissão como espetáculo, pelas tensões que criam nos indivíduos, nos grupos sociais e nos povos. São transmissíveis como infecções. A diferença principal é que não há remédios ou vacinas contra elas, e que seu combate requer principalmente anticorpos sociais e culturais.

Tenho a impressão de que perante as formas de violência (e os tóxicos), além da tendência ao isolamento prevalece às vezes a rejeição ou aceitação seletiva, variável conforme as tipologias e as causas da violência ou de seus autores e vítimas. Dentro de nós aprovamos ou apagamos as formas de violência que não nos tocam diretamente, ou que correspondem às cristalizações e deformações de nosso sistema mental e dos interesses dominantes. Assim, impedimos que essas formas de violência aflorem à consciência crítica. Creio que modificar essa atitude é a condição preliminar para enfrentar globalmente o problema da violência.

\section{Algumas conclusões}

Este texto representa para o autor um primeiro esboço, sem pretensões de ser orgânico e suscetível de complementações posteriores. Assim, 
também as teses expostas, vista a complexidade do assunto, são passíveis de alterações e atualizações com base em fatos, reflexões do próprio autor e sugestões alheias.

A seleção dos quatro fenômenos que levam a por em primeiro plano a saúde global é discutível, não é exclusiva, e requer muitas outras especificações. Mas esses fenômenos têm algumas características comuns. A primeira é que o dano atinge de modo seletivo, embora não-exclusivo, pessoas, classes e povos, em proporção inversa à riqueza, à instrução e ao poder, introduzindo ou reforçando as condições de desigualdade. A segunda é que as ameaças se tornam sempre mais globais e, por isso, há novas e maiores motivações empíricas para associar o interesse imediato dos indivíduos e dos povos a um diveito moral universal. A terceira, que enuncio de modo ainda mais sumário que as anteriores, é que desses fenômenos, quase sempre, alguém tira proveito. A quarta, que já expus em linhas gerais no final do tópico Antigas e novas infecções, ao falar da transição epidemiológica, é que tanto as infecções quanto a poluição, os tóxicos e as formas de violência são hoje em grande parte antropogênicos, isto é, não se devem à natureza ou ao acaso, mas a opções humanas. Assim, são modificáveis com base em atos de vontade, hoje impostos pela consciência e pela necessidade.

Os pontos de conclusão apresentados a seguir, que me parecem os mais relevantes, tampouco são exclusivos e cada qual exigiria maiores argumentos e especificações.

- Reequilibrar os poderes e as metas. A globalização não é uma palavra infeliz, uma invenção perversa do neoliberalismo. A globalização é uma tendência positiva da espécie homo sapiens sapiens que atingiu o grau atual de conhecimentos e desenvolvimento. Se essa tendência é vista de modo negativo, isso se dá porque até agora a globalização tem estado fortemente desequilibrada em termos de poder e de metas. São essas as características que é preciso modificar.

No campo do poder, há que limitar o arbítrio de alguns países (os sete ou oito países mais ricos) que se arrogam o direito de decidir por todos, bem como o poder das instituições monetárias, que pretendem subordinar a seus interesses todas as atividades humanas. Por outro lado, em sentido positivo, há que abrir caminho para uma democracia universal, na qual se faça ouvir mais a voz de todos os povos e de todos os interesses, tanto por meio de organizações intergovernamentais (como a ONU e a OMS) quanto por meio de organizações não-governamentais. 
No campo das metas, há que por em primeiro plano (ou, mais modestamente, há que ao menos reconduzir à cena, de onde quase se retiram) os direitos humanos fundamentais e o tema da igualdade. É nesse campo que se colocam a saúde e a segurança como direito à vida e como condição para o exercício de todas as liberdades.

- Solidariedade e conveniência. Como estímulos aptos a favorecer essas metas, vem-se falando, com razão, em valores morais, tais como a universalidade, a solidariedade, a justiça. Estímulos necessários, mas não suficientes. Deve-se também falar em interesse recíproco, em vantagem mútua. O humanitarismo é uma força importante, mas há outra, a conveniência, que nem sempre se opõe a ele. Até mesmo o utilitarismo e o contratualismo, interpretados como altruismo conveniente, podem convergir nessas metas, porque a saúde é bem não só individual, mas indivisível. É o que se vê pelo fato de os cidadãos de sociedades coesas e justas serem também, em média, os mais saudáveis. Além disso, a saúde não é balanço sem déficit nem superávit, algum bem que baste distribuir com mais igualdade. De fato, a maior igualdade na saúde é fator multiplicador desse bem. Assim, o humanitarismo e o interesse, que muitas vezes foram contrapostos, também podem se unir e tornar o caminho mais rápido e consistente.

A saúde global não exige somente medidas de caráter científico e social. Não se pode consegui-la sem progresso cultural e moral. A reflexão bioética desenvolveu-se nas últimas décadas de modo tumultuado, enfrentando sobretudo casos situados nas fronteiras mais avançadas da ciência, mas descuidando-se da existência e dos sofrimentos das grandes multidões humanas.

Por vezes a bioética transformou-se em bioética justificativa, aplicada em fornecer argumentos filosóficos a posteriori para legitimar opções adversas aos direitos humanos, como a compra e venda de órgãos humanos e o racionamento de tratamentos. Alastair Campbell, presidente da Associação Internacional de Bioética, comparou com crueza os estudiosos de bioética que sustentam essas teses a bispos que batizam navios de guerra e ressaltou algo que já vem ocorrendo: que a bioética deve se empenhar sempre mais no tema da saúde humana, individual e coletiva.

- Os sistemas de previdência e bem-estar (welfare). O fundamentalismo monetário tende a impor a idéia de que os sistemas de previdência e bem-estar nada mais são do que um parêntesis histórico, antes do qual as incógnitas da vida (nascer, crescer, adoecer, trabalhar, ficar 
desempregado, envelhecer) só eram regidos pelo acaso e pela riqueza. Depois desse parêntesis, devem voltar as regras da seleção selvagem do salve-se quem puder.

Na realidade histórica, o Estado social decerto não foi empecilho ao crescimento econômico. Pelo contrário, acompanhou-o e lhe deu apoio. Foi o Estado social que representou, principalmente (mas não só) na Europa, uma síntese feliz entre democracia política, livre mercado, progresso científico e justiça social. Foi também ele que produziu, entre os cidadãos, condições de saúde melhores que as de qualquer outro sistema. Na realidade atual, depois de 20 anos de hegemonia neoliberal, não há demonstração alguma de que as promessas neoliberais de melhora da saúde e da assistência médica se tenham cumprido. Pelo contrário: o progresso havido nas décadas anteriores foi retardado e cresceram todas as desigualdades.

Mas os sistemas de previdência e bem-estar se desgastaram, não só por ataques externos, como também (e talvez mais) por suas próprias contradições. Por exemplo, houve desgaste por não se ter sabido criar equilíbrio de direitos e tutelas entre gerações e sexos (quase sempre com prejuízo dos jovens e das mulheres); por não se ter assegurado suficiente igualdade na saúde e suficiente prioridade aos tratamentos fundamentais e à prevenção de doenças; por não haver acrescentado à proteção oficial a contribuição da sociedade civil e a responsabilização de particulares. Por isso, não há defesa possível do estado social sem sua profunda transformação.

- Governo global. Não pode haver saúde global sem governo global. A idéia de governo global foi proposta por Immanuel Kant e retomada muitas vezes nos séculos posteriores, quer com intuitos hegemônicos, quer com finalidades humanitárias. Albert Einstein, por exemplo, reformulou-a em novembro de 1945, a fim de restringir o poder destruidor das bombas nucleares. Hoje há exigências prementes de $u m$ poder democrático universal, para governar fenômenos que vão dos fluxos de capitais à poluição ambiental e ao comércio de armas que ultrapassem barbaramente as fronteiras dos Estados. Tal governo é ainda mais necessário para guiar o desenvolvimento no rumo de metas humanas.

Foi o que em parte ocorreu no campo da saúde, no início do século atual. Mas depois da unificação microbiana do mundo, tendo os continentes passado do isolamento à comunicação, ainda foram precisos mais de 300 anos antes da formação da consciência da independência 
e do início da primeira globalização da saúde e da segurança. Diante dos riscos comuns, que resumi nas quatro ameaças principais, não podemos esperar mais três séculos. Nem três décadas. Isso é de interesse vital para as populações, para a convivência civilizada e também para todos os que trabalham no campo da saúde, da segurança, da qualidade de vida.

Se não se inverter a tendência, um duplo conflito há de se agravar para todos nós e para a sociedade em que vivemos. Conflito entre a moral e a atividade prática quotidiana: por um lado, ser chamado e obrigado a reparar, tardia e insuficientemente, os danos previsíveis e preveníveis causados à saúde e à integridade humana; por outro, ter de fazê-lo com meios técnico-científico mais aperfeiçoados, sim, mas em condições social e economicamente mais difíceis, com recursos e apoio públicos menores. Pode-se até ser chamado a decidir, entre esta e aquela pessoa, a quem cabe ou não viver. Abismo moral, para profissões e atividades originadas e desenvolvidas para trabalhar a favor de todas as vidas humanas, e drama para quem tiver de governar em tais condições os destinos da coletividade.

ABSTRACT - THIS PAPER IS A critical analysis focusing on the globalization issue, the positive and negative evaluations made on it, the opposition to the World Bank and IMF proposals, and the question of equity and health care. The conclusion emphasizes the necessity for powers and purposes to strike a new balance between them. Globalization is not a dirty word, a perverse invention of neoliberalism. It is time we thought of a universal Democracy comprizing more than just seven or eight countries, one that should fight for equity and basic human rights; one that may promote the community of interest while opposing the idea that the Welfare State was a "historical parenthesis" and is now outdated. It is time we thought seriously of a global government.

Giovanni Berlinguer, médico, é professor da Universidade La Sapienza, em Roma, e ex-senador.

Tradução de Pedro Garcez Ghirardi. O texto original - Globalizzazione e salute globale - encontra-se à disposição do leitor no IEA-USP para eventual consulta. 